Correction

\title{
Correction: Chae, H.S., et al. Anti-Inflammatory Effects of 6,8-Diprenyl-7,4'-dihydroxyflavanone from Sophora tonkinensis on Lipopolysaccharide-Stimulated RAW 264.7 Cells. Molecules. 2016, 21, 1049.
}

Hee-Sung Chae ${ }^{1}$, Hunseung Yoo ${ }^{2}$, Young-Mi Kim ${ }^{1}$, Young Hee Choi ${ }^{1}$, Chang Hoon Lee ${ }^{1}$ and Young-Won Chin 1,*

1 College of Pharmacy, Dongguk University-Seoul, 32 Dongguk-lo, Ilsandong-gu, Goyang-si,

Gyeonggi-do 410-820, Korea; chaeheesung83@gmail.com (H.-S.C.); 0210121@hanmail.net (Y.-M.K.);

choiyh@dongguk.edu (Y.H.C.); uatheone@dongguk.edu (C.H.L.)

2 New Drug Preclinical \& Analytical Team, Life Science R \& D Center, SK Chemicals, 310 Pangyo-ro 463-400,

Korea; yoohoo0733@naver.com

* Correspondence: f2744@dongguk.edu; Tel.: +82-31-961-5218

Academic Editor: Derek J. McPhee

Received: 12 October 2016; Accepted: 19 October 2016; Published: 24 October 2016

The authors wish to make the following correction to their paper [1]. In Panel C of Figure 4, the data was incorrectly displayed. The correct version of Figure $4 \mathrm{C}$ is as follows:
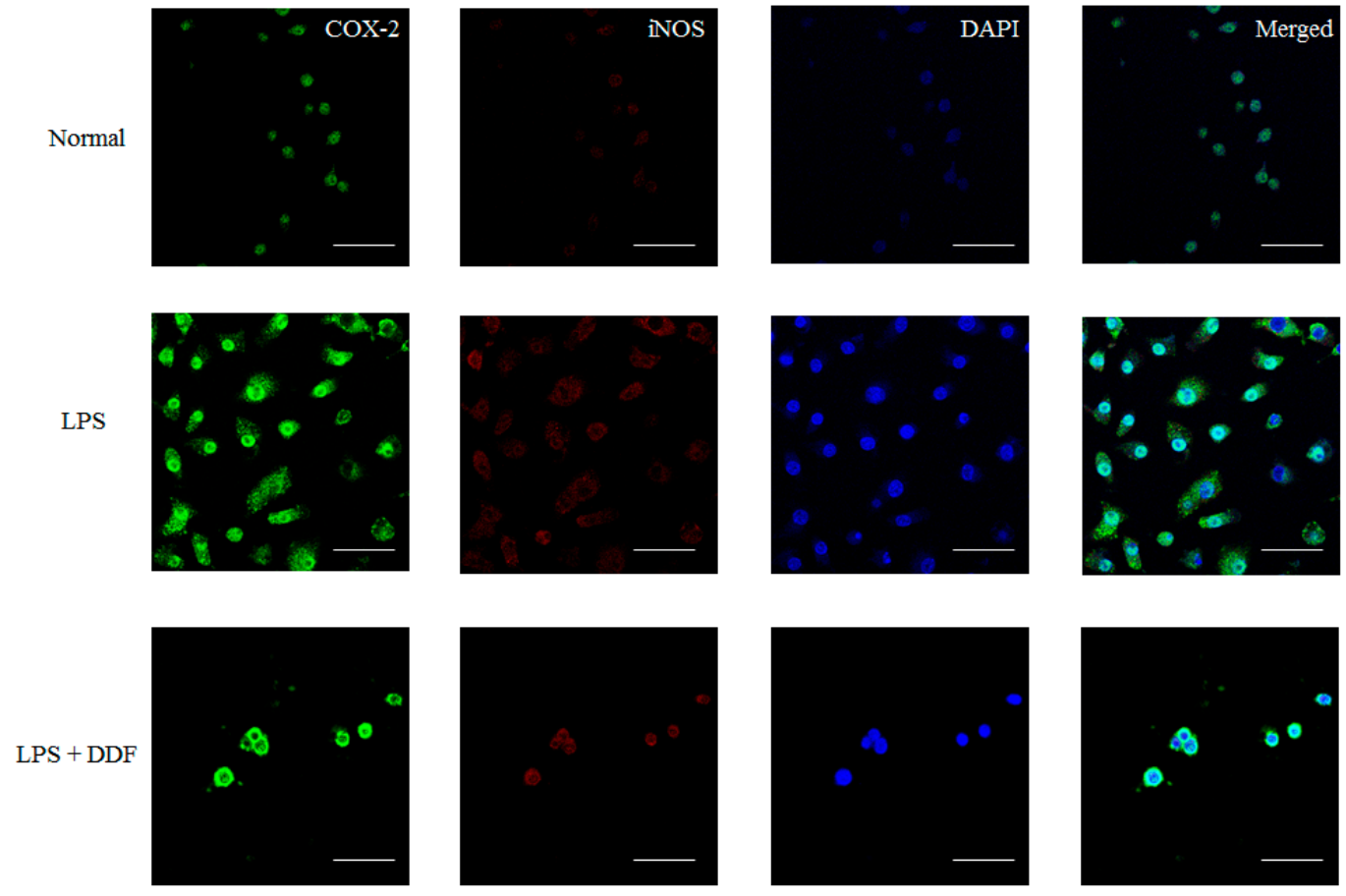

Figure 4. (C) Expression of iNOS and COX-2 with DDF. Cells were cultured for $24 \mathrm{~h}$ with LPS $(250 \mathrm{ng} / \mathrm{mL})$, fixed, permeabilized, and incubated with rabbit polyclonal anti-iNOS antibody, followed by Alexa-488-conjugated anti-rabbit Ig (green); and with mouse polyclonal anti-COX-2 antibody followed by Alexa-594-conjugated anti-mouse Ig (red); The nuclei of the corresponding cells were visualized by DAPI staining (blue). Normal, untreated control cells; LPS, treatment with only LPS (250 ng/mL); DDF, 6.8-diprenyl-4',7-dihydroxyflavanone; (magnification: 60×, scale bars: $50 \mu \mathrm{m}$ ). 
The change does not affect the scientific results. The manuscript will be updated and the original will remain online on the article webpage. The authors would like to apologize for any inconvenience caused to readers by these changes.

\section{Reference}

1. Chae, H.S.; Yoo, H.; Kim, Y.M.; Choi, Y.H.; Lee, C.H.; Chin, Y.W. Anti-Inflammatory Effects of 6,8-Diprenyl-7,4'-dihydroxyflavanone from Sophora tonkinensis on Lipopolysaccharide-Stimulated RAW 264.7 Cells. Molecules 2016, 21, 1049. [CrossRef] [PubMed]

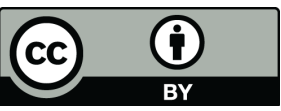

(c) 2016 by the authors; licensee MDPI, Basel, Switzerland. This article is an open access article distributed under the terms and conditions of the Creative Commons Attribution (CC-BY) license (http://creativecommons.org/licenses/by/4.0/). 